\title{
PEMANFAATAN LIMBAH UDANG (KEPALA DAN KULIT UDANG) SEBAGAI BUBUK KALDU PENGGANTI MSG DI DESA MEDALEM SIDOARJO
}

\author{
Elvira Mustikawati Putri Hermanto ${ }^{1)}$, Khoirun Nisak Alfiyatun Nengseh ${ }^{2)}$ \\ ${ }^{1}$ Fakultas Matemaika dan Ilmu Pengetahuan Alam Universitas PGRI Adi Buana Surabaya \\ ${ }^{2}$ Fakultas Keguruan dan Ilmu Pendidikan Universitas PGRI Adi Buana Surabaya \\ Email: ${ }^{1}$ elvira.mustikawati@gmail.com, ${ }^{2}$ khoirunnisak404@gmail.com
}

\begin{abstract}
Abstrak
Industri kuliner di Indonesia meningkat dengan pesat. Berdasarkan data dari Badan Ekonomi Kreatif, lebih dari $40 \%$ perekonomian kreatif berasal dari kuliner. Saat ini, kuliner yang menyeimbangkan gaya hidup sehat mulai digemari. Salah satunya yang mengusung konsep tanpa MSG. Berdasarkan informasi tersebut, kegiatan pengabdian masyarakat dengan tema pemanfaatan limbah udang sebagai bubuk kaldu pengganti MSG dilakukan di Desa Medalem. Kegiatan dilakukan dengan dua agenda, yaitu sosialisasi bahaya MSG dan memberikan beberapa alternatif pilihan bahan pengganti MSG serta kandungannya. Agenda kedua adalah praktik pembuatan kaldu limbang udang sebagai bahan pengganti MSG. Bahan yang digunakan adalah kepala dan kulit udang yang biasanya terbuang ternyata dapat digunakan sebagai penyedap rasa dan kaya manfaat. Limbah udang disebut kaya antioksidan daripada sayuran dan buah. Kegiatan diikuti oleh 20 peserta yang merupakan anggota PKK. Hasil dari kegiatan ini adalah peserta mempunyai pilihan bahan dan keterampilan untuk mengolah bahan tersebut menjadi pengganti MSG yang lebih sehat. Selain itu peserta mengetahui teknik penyimpanan bubuk kaldu. Produk yang dihasilkan adalah bubuk kaldu hasil praktikum yang kemudian dilakukan pengemasan diakhir praktikum. Peserta antusias mengikuti jalannya kegiatan dari awal sampai akhir kegiatan.
\end{abstract}

Kata Kunci: Kuliner, Gaya Hidup Sehat, Pengganti MSG, Limbah Udang

\begin{abstract}
The Culinary Industry in Indonesia is growing rapidly. Based on data from the Creative Economy Agency, more than $40 \%$ of the creative economy comes from culinary. At present, to balance a healthy lifestyle, a variety of culinary developments are culinary without MSG. Community service activities were carried out in Desa Medalem, Kabupaten Sidoarjo. In this activity socialization of the dangers of using MSG was socialized and provided several choices of MSG substitutes. One of them is the utilization of shrimp waste, namely the head and skin of shrimp. The material was chosen because of its benefits as an antioxidant that is better than vegetables and fruit. In addition to socialization, there is the practice of making shrimp waste broth for MSG substitutes. This activity was welcomed by the enthusiasm of the residents and was attended by around 20 participants.
\end{abstract}

Keywords: Culinary, Healthy lifestyle, MSG, head and skin of shrimp 


\section{PENDAHULUAN}

Industri kuliner di Indonesia telah mengalami kemajuan yang cukup pesat. Bisnis kuliner tengah menjamur di kalangan masyarakat Indonesia mulai menjadi gaya hidup. Berdasarkan data Badan Ekonomi Kreatif Republik Indonesia (2018) 41.5\% dari total kontribusi perekonomian kreatif berasal dari subsektor kuliner. Industri kuliner memiliki potensi yang besar untuk terus berkembang. Pengembangan industri kuliner dapat terus ditingkatkan dengan beberapa hal, salah satunya adalah inovasi dalam menu makanan.

Berkembangnya industri kuliner berbanding positif dengan kesadaran masyarakat terhadap gaya hidup sehat. Mudahnya informasi digali membuat masyarakat sadar akan pentingnya kesehatan. Salah satu tren menjaga kesehatan saat ini adalah membatasi asupan penyedap rasa atau yang biasa dikenal dengan MSG (Monosodium Glutamate).

MSG adalah zat tambahan yang ditambahkan dalam olahan makanan atau minuman dengan tujuan untuk penyedap atau penguat rasa. Meskipun dalam jumlah tertentu MSG dikatakan aman dikonsumsi, tetapi saat ini bisnis kuliner tanpa MSG mulai menjamur di masyarakat. Terdapat beragam makanan yang diklaim tanpa MSG yang mulai dijual dipasaran, mulai dari keripik hingga makanan rumahan.

Terdapat beberapa cara mengganti MSG dengan bahan alami lain. Salah satunya dengan limbah bahan makanan yang biasanya terbuang, yaitu kepala dan kulit udang. Baskoro (2016) menyebutkan bahwa kepala dan kulit udang dapat diolah menjadi kaldu yang dapat menimbulkan cita rasa gurih terhadap olahan makanannya. Selain dapat digunakan sebagai penambah cita rasa, kulit udang mempunyai manfaat melawan radikal bebas sepuluh kali lebih baik daripada buah dan sayur karena mengandung antioksidan astaxanthin (detikhealth, 2013).

Desa Medalem terdapat di Kecamatan Tulangan di Kabupaten Sidoarjo. Desa Medalem mempunyai 12 RT dan total kepala keluarga sebesar 946 KK. Sebagian besar penduduk Desa Medalem berprofesi sebagai karyawan swasta.

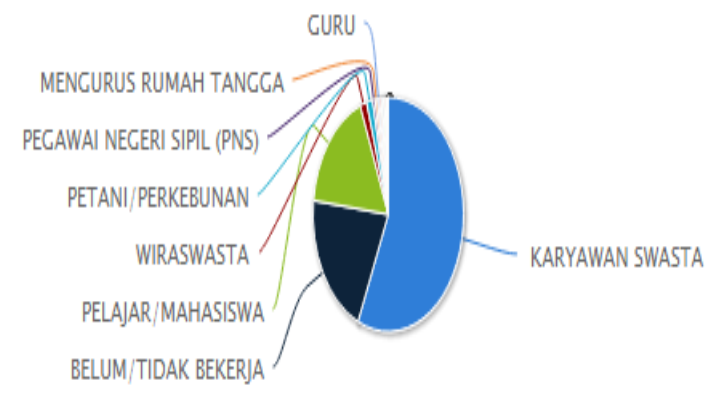

Gambar 1. Statistik Demografi Pekerjaan

Penduduk Desa Medalem (Sumber: http://sid.sidoarjokab.go.id)

Berdasarkan uraian tersebut, tujuan kegiatan pengabdian masyarakat ini adalah mengedukasi masyarakat di Desa Medalem pentingnya makanan sehat dan memberikan informasi cara memanfaat dan mengolah kepala dan kulit udang sebagai bahan pengganti MSG agar tidak terbuang.

\section{METODE PELAKSANAAN}

Peserta kegiatan adalah ibu-ibu PKK di Desa Medalem. Kegiatan dibagi menjadi dalam dua tahapan, yaitu:

1. Penyuluhan: sosialisasi dengan materi definisi MSG, efek samping MSG, berbagai macam bahan dan kandungan gizi sebagai penyedap alternatif pengganti MSG, dan bahan dan langkah-langkah pengelolahan kaldu dengan limbah udang.

2. Pelatihan praktik dengan kegiatan membuat dan mengemas kaldu kepala dan kulit udang sebagai pengganti MSG 
Bahan untuk membuat kaldu dengan limbah udang adalah sebagai berikut.

1. 300 gram limbah udang (kepala, kulit dan ekor udang) dihaluskan

2. 15 siung bawang putih yang sudah dibersihkan

3. 1 bawang bombay yang sudah dibersihkan

4. $1 \mathrm{buah} / 100 \mathrm{gr}$ wortel (potong-potong)

5. 10 butir ketumbar

6. 2 batang seledri

7. 1 batang daun bawang

8. $2 \mathrm{sdm}$ garam atau sesuai selera

Semua bahan tersebut dicampur menjadi satu kemudian dihaluskan atau digiling. Selanjutnya kaldu diperoleh melalui metode pengeringan. Metode pengeringan ini dapat dilakukan dengan cara memanasi kaldu diatas wajan dengan api kecil. Selama proses pengeringan kaldu diaduk terus menerus sampai kaldu sudah berpasir.

\section{HASIL DAN PEMBAHASAN}

Hasil kegiatan pengabdian ini adalah antusiasme warga untuk mencari bahan-bahan alami sebagai bahan pengganti MSG yang selama ini digunakan untuk penguat rasa. Kegiatan sosialisasi dan praktikum pembuatan kaldu dari limbah udang untuk pengganti MSG dilaksanakan di Balai Desa Medalem pada Minggu, 3 Februari 2019. Peserta yang hadir sebanyak 20 peserta anggota PKK. Hasil yang dicapai adalah pengetahuan peserta mengenai MSG berserta efek samping MSG bertambah. Selain itu peserta kegiatan mengetahui bahan-bahan yang dapat digunakan untuk penyedap dan penguat rasa.

Bahan yang digunakan adalah bahan yang biasanya terbuang seperti kepala, kulit, dan ekor udang. Berdasarkan pemaparan yang diberikan, peserta mengetahui kandungan dalam limbah udang serta bahan makanan lainnya. Peserta juga antusias mengikuti kegiatan praktikum pembuatan MSG dengan bahan limbah udang. Produk yang dihasilkan dari kegiatan ini adalah bubuk kaldu hasil praktikum yang bisa dibawa pulang.

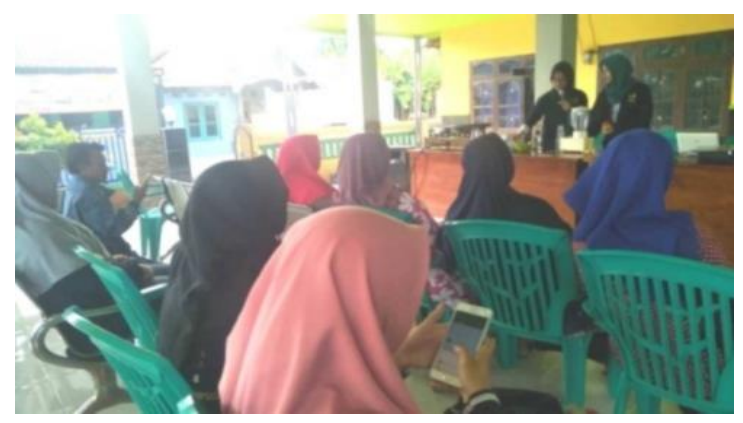

Gambar 2. Suasana Kegiatan Pengabdian Pemanfaatan Limbah Udang sebagai Bubuk Kaldu Pengganti MSG

\section{KESIMPULAN}

Kegiatan berjalan dengan lancar. Peserta antusias mengikuti jalannya kegiatan. Adanya kegiatan ini peserta telah mengetahui bahaya dari MSG dan mengetahui bahan-bahan yang dapat terpakai untuk mengganti MSG.

\section{REFERENSI}

Baskoro, D. 2016. Kulit Udang Dimakan atau Dibuang? Simak Ini. https://lifestyle.okezone.com/read/2016 /10/03/298/1505055/kulit-udangdimakan-atau-dibuang-simak-ini. Diakses tanggal 10 Maret 2019.

Badan Ekonomi Kreatif. Kuliner. http://www.bekraf.go.id/subsektor/page /kuliner. Diakses tanggal 10 Maret 2019.

DetikHealth. 2013. Dianggap Sisa dan Selalu Terbuang, Padahal Banyak Manfaat Sehatnya. https://health.detik.com/hidup-sehatdetikhealth/d-2275792/dianggap-sisadan-selalu-terbuang-padahal-banyakmanfaat-sehatnya. Diakses tanggal 10 Maret 2019. 
http://sid.sidoarjokab.go.id/tulangan-

Medalem/index.php/first/statistik/1. Diakses

tanggal 10 Maret 2019. 